\title{
Knowledge and Awareness of Halitosis Causes among Taibah University Students in Al-Medinah, Saudi Arabia, 2017
}

\author{
Bader Alim* , Afaf Aljohani², Sahal Arabi², Heba Almahdi², Ghadeer Jumah ${ }^{2}$ and Zoubayda Alazhari ${ }^{3}$ \\ ${ }^{1}$ Department of ENT, King Abdulaziz University Hospital, Saudi Arabia \\ ${ }^{2}$ Faculty of Medicine, Taibah University, Saudi Arabia \\ ${ }^{3}$ Dental department, Prince Sultan armed forces hospital, Saudi Arabia
}

Submission: December 21, 2017; Published: January 03, 2018

*Corresponding author: Bader Mohammed Alim, King Abdulaziz university hospital, Riyadh 11411, Kingdom of Saudi Arabia, Tel: +966541800096; Email: dr.badrmalam@hotmail.com

\begin{abstract}
Background: Halitosis is a significant change in breath odour that has a negative social impact, affecting many people around the world. It can cause social and personal isolation, decrease the quality of life and may indicate the presence of a more severe disease.

Objectives: This study was conducted to assess the knowledge and awareness levels of the causes of halitosis among Taibah University students in AL-Medinah city, Saudi Arabia.
\end{abstract}

Methods: A self-administered electronic questionnaire on knowledge and awareness of the causes of halitosis was distributed on a randomly selected sample of students from Taibah University.

Results: The response rate was $45 \%$ (540). Our questionnaire revealed that most respondents thought halitosis was normal after eating strong-smelling food (92\%), sleeping (72\%) and smoking (71\%). Ninety-seven percent of the participants said that oral diseases are the most common causes, while only $40 \%$ considered the stomach to be the most frequent pathological cause. Great percentages $(<55 \%)$ related nine causes of bad breath (out of the given 15) to halitosis. According to 315 (58\%) respondents, dentists are the most qualified specialists to treat halitosis and only $53(9 \%)$ thought that halitosis patients should be referred to ENT specialists. Finally, more than half the population said they had not received any education about halitosis.

Conclusion: This finding demonstrates that knowledge and awareness about halitosis causes seem to be insufficient among Taibah University students. Therefore, health officials must increase their efforts in educating the society about this serious problem.

Keywords: Halitosis; Awareness; Risk Factors

\section{Introduction}

Halitosis, bad breath or malodour are medical terms used to define a pathological process that is manifested by the presence of any bad, unpleasant or offensive breath emitted consistently from a person's mouth [1-3]. It is considered as a common oral health problem throughout the world. More than $50 \%$ of the general population have halitosis [1,4-6]. In Riyadh, Saudi Arabia, the prevalence of self-perceived halitosis among the population is within the range reported in other countries [7]. Although the origin of halitosis in $90 \%$ of the cases is oral cavity, halitosis has multifactorial origins [8]. About $9 \%$ of the cases of halitosis are caused by non-oral reasons, such as the respiratory system, gastrointestinal system or urinary system, and in the remaining $1 \%$ of patients, the cause of halitosis is extrinsic due to either diets or drugs $[9,10]$. Approximately, $10 \%$ of the oral malodour cases originate from the ears, nose and throat
(ENT) region, of which tonsils are responsible for $3 \%$ of the oral malodour as cases of tonsillitis. The larynx is rarely involved. Therefore, when a clinical investigation is performed, attention should first be directed towards the tonsils $[11,12]$. Conditions such as Plaut-Vincent angina, postnasal drip, and foreign bodies in the nasal cavity, sinusitis and others can cause oral malodour [13-16].

Halitosis can cause major social impacts on those who suffer from it and may profoundly affect their normal daily life activities, including daily communication with others during social and professional interactions. Additionally, it can affect the individual's self-esteem and confidence, cause embarrassment and reduce employment and career opportunities, thereby decreasing the quality of life $[17,18]$. Halitosis can be detected, either directly or indirectly, by using many methods. 


\section{Global Journal of Otolaryngology}

The most commonly used diagnostic methods include gas chromatography, organoleptic (hedonic) measurement, sulphide monitoring, the BANA test and the use of chemical sensors [19]. To our knowledge, there are no studies that have assessed the knowledge and attitude towards halitosis among the Medinah population. Moreover, limited information is available on the relationship of socio-demographic factors, oral hygiene habits, symptoms of periodontal disease and self-confidence in the social life of patients with halitosis [20]. Therefore, this study was conducted to assess the knowledge and attitude of the Saudi students at Taibah University towards self-perceived oral and extra-oral causes of halitosis.

\section{Materials and Methods}

A self-administered cross-sectional electronic questionnaire was distributed among 1200 randomly chosen students in Taibah University between March-May 2017. Prior to including any participant in this study, consent was taken after explaining the objectives and methodology of the study. The inclusion criteria required participants to be Saudi, adult and regular students at Taibah University. Privacy and confidentiality of the participants were assured. The questionnaire contained three main sections: socio-demographic (age, gender, education level, nationality, marital status and specialty),basic knowledge (physiological and pathological causes of halitosis, most frequent cause, proper ways for managing halitosis and personal impact of halitosis) and advanced knowledge (standard diagnostic tools for halitosis and medical causes or conditions which can cause halitosis). Data entry was done using Excel sheets. The data was analysed using SPSS version 20. The data was presented using frequencies, means, and standard deviation. Bivariate analysis was conducted to test significant differences. The chi-square test was used for qualitative variables and student's t-test was applied for quantitative variables. $\mathrm{P}<0.05$ was considered to be significant.

\section{Results}

\section{Study population}

Of the 1,200 subjects contacted, 540 agreed to participate and filled out the questionnaire, giving an overall response rate of $45 \%$. Of these, 304 (56.3\%) were female and 236 (43.7\%) were male.77.2\% of the participants were between the ages of 18-24 years and $73.5 \%$ were single. The vast majority of the participants, i.e. 502 participants (95.4\%), were Saudi. Two hundred twenty-four $(41.5 \%)$ were from medical colleges and $316(58.5 \%)$ were from non-medical colleges (Table 1$)$.

Table 1: Sociodemographic data of respondents $n=540$.

\begin{tabular}{|c|c|c|}
\hline Variables & $\mathrm{n}=\mathbf{5 4 0}$ & $\%$ \\
\hline \multicolumn{3}{|l|}{ Gender } \\
\hline Male & 236 & 43.7 \\
\hline Female & 304 & 56.3 \\
\hline \multicolumn{3}{|l|}{ Age } \\
\hline $18-24$ years & 417 & 77.2 \\
\hline $25-34$ years & 77 & 19.3 \\
\hline $35-44$ years & 41 & 7.6 \\
\hline $45-55$ years & 5 & 0.9 \\
\hline \multicolumn{3}{|l|}{ Marital status } \\
\hline Married & 136 & 25.2 \\
\hline Single & 397 & 73.5 \\
\hline Divorced & 7 & 1.3 \\
\hline \multicolumn{3}{|l|}{ Nationality } \\
\hline Saudi & 512 & 95.4 \\
\hline Other & 25 & 4.6 \\
\hline \multicolumn{3}{|l|}{ Specialty } \\
\hline Medical specialty & 224 & 41.5 \\
\hline Non-medical specialty & 316 & 58.5 \\
\hline \multicolumn{3}{|l|}{ Degree } \\
\hline Bachelor & 516 & 95.6 \\
\hline Master & 19 & 3.5 \\
\hline $\mathrm{PhD}$ & 5 & 0.9 \\
\hline \multicolumn{3}{|l|}{ College year } \\
\hline 1st year & 89 & 16.5 \\
\hline
\end{tabular}




\section{Global Journal of Otolaryngology}

\begin{tabular}{|l|l|l|}
\hline $2^{\text {nd }}$ year & 74 & 13.5 \\
\hline $3^{\text {rd }}$ year & 131 & 24.3 \\
\hline $4^{\text {th }}$ year & 102 & 18.9 \\
\hline $5^{\text {th }}$ year & 144 & 26.7 \\
\hline
\end{tabular}

\section{Questionnaire analysis}

Table 2: Physiological or pathological halitosis for some situations ( $=540(100 \%))$.

\begin{tabular}{|c|c|c|}
\hline Situation & Physiological & Pathological \\
\hline $\begin{array}{c}\text { Halitosis after eating some smelly } \\
\text { food }\end{array}$ & $498(92.2 \%)$ & $42(7.8 \%)$ \\
\hline $\begin{array}{c}\text { Halitosis after sleeping for healthy } \\
\text { people }\end{array}$ & $390(72.2 \%)$ & $150(27.8 \%)$ \\
\hline Halitosis after smoking & $385(71.3 \%)$ & $155(28.7 \%)$ \\
\hline
\end{tabular}

Among the three different situations given to the participants to detect halitosis (after eating some strong-smelling food, after sleeping for healthy people, and after smoking), the majority said that it is physiological to have halitosis in these situations (92.2\%),(72.2\%) and (71.3\%), respectively (Table 2). We mentioned 15 different causes of halitosis and asked the participants to decide (yes or no) if each item was a cause of halitosis, and we put the answer (maybe a cause) for those who were unsure. The three most opted causes for halitosis were eating certain types of food (80\%), smoking (87.6\%) and the presence of cavities in teeth (64.6\%).On the other hand, stress $(57.2 \%)$, liver diseases $(41.7 \%)$ and rhinitis $(33.5 \%)$ were the three causes that were chosen as not leading to halitosis. Taking certain types of medications was heeded as a likely cause by most (37.6\%) (Table 3). Regarding the pathologic causes of halitosis, $429(79.4 \%)$ participants thought that halitosis occurs from intra-oral sources, while only 111 (20.6\%) participants said that it's from extra-oral sources like skin and hair (Figure 1). Less than half the participants $(40.7 \%)$ believed that the stomach is the most common source of halitosis and the second chosen source was the tongue $(20.9 \%)$, followed by gums $(17.2 \%)$ (Figure 2).

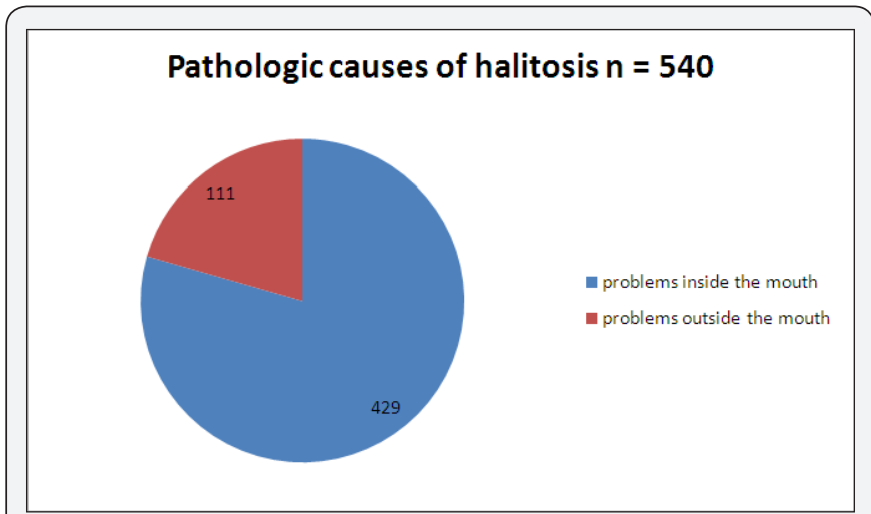

Figure 1: Pathologic causes of halitosis.

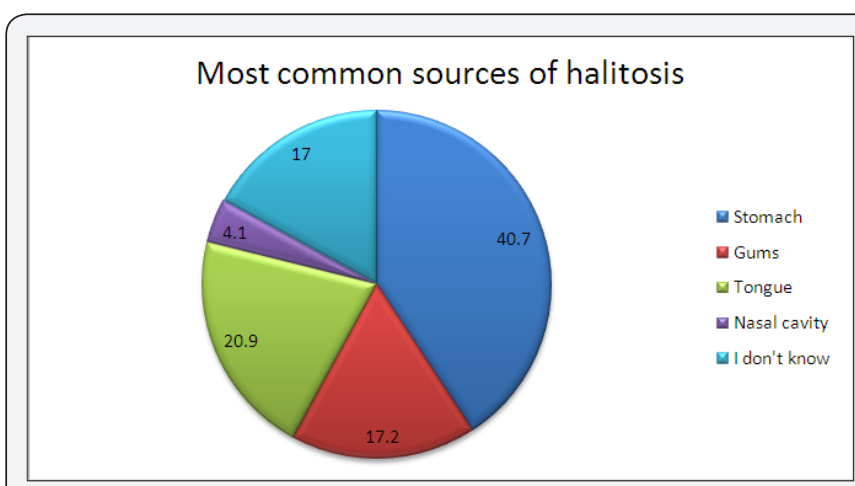

Figure 2 : Most common sources of halitosis.

Table 3: The relation between halitosis and different causes. $(n=540(100 \%))$.

\begin{tabular}{|c|c|c|c|}
\hline \multirow{2}{*}{ The cause } & \multicolumn{3}{|c|}{ Is there a relation? } \\
\cline { 2 - 4 } & Yes & No & Maybe \\
\hline Cleaning teeth by incorrect way & $341(63.1 \%)$ & $52(9.6 \%)$ & $147(27.2 \%)$ \\
\hline Cleaning tongue by incorrect way & $308(57 \%)$ & $63(11.7 \%)$ & $169(31.3 \%)$ \\
\hline Presence of cavities in the teeth & $349(64.6 \%)$ & $69(128 \%)$ & $122(22.6 \%)$ \\
\hline Bleeding gums & $325(60.2 \%)$ & $87(16.1 \%)$ & $128(23.7 \%)$ \\
\hline Dry mouth & $323(59.8 \%)$ & $82(15.2 \%)$ & $49(9.1 \%)$ \\
\hline Smoking & $373(87.6 \%)$ & $18(3.3 \%)$ & $88(16.3 \%)$ \\
\hline Eating some types of food & $432(80 \%)$ & $20(3.7 \%)$ & $121(22.4 \%)$ \\
\hline Tonsillitis & $301(55.7 \%)$ & $118(21.9 \%)$ & $181(33.5 \%)$ \\
\hline Rhinitis & $195(36.1 \%)$ & $135(25 \%)$ & $172(31.9 \%)$ \\
\hline Accumulation of mucus at the back of throat & $233(43.1 \%)$ & $156(28.9 \%)$ & $153(28.3 \%)$ \\
\hline Lung diseases & $231(42.8 \%)$ & & \\
\hline
\end{tabular}




\section{Global Journal of Otolaryngology}

\begin{tabular}{|c|c|c|c|}
\hline Liver diseases & $179(33.1 \%)$ & $225(41.7 \%)$ & $136(23.2 \%)$ \\
\hline GIT diseases & $306(56.7 \%)$ & $94(17.4 \%)$ & $140(25.9 \%)$ \\
\hline Stress & $88(16.3 \%)$ & $309(57.2 \%)$ & $143(26.5 \%)$ \\
\hline Some types of medication & $222(41.1 \%)$ & $115(21.3 \%)$ & $203(37.6 \%)$ \\
\hline \multirow{2}{*}{ Do you think these are all the causes? } & \multicolumn{2}{|c|}{$443(82 \%)$} & No \\
\cline { 2 - 4 } & \multicolumn{2}{|c|}{$97(18 \%)$} \\
\hline
\end{tabular}

Regarding the level of knowledge about the diagnosis and solutions of halitosis, almost half the participants $(52.4 \%)$ stated that they did not know how to diagnose and treat halitosis. When asked who should treat patients with halitosis, $58.3 \%$ of the participants recommended dentists, whereas $15.9 \%$ recommended gastroenterologists and $15.2 \%$ recommended general practitioners. ENT specialists were the least chosen option (9.8\%). Regarding the correct way to deal with halitosis, participants were divided mainly between seeing a doctor (45.6\%) and using mouthwash (35.9\%). Most participants thought it was easy to treat halitosis (65.6\%) (Table 4). Participants were asked to evaluate educational material received about halitosis; the majority (53.7\%) reported that they did not receive any (Figure 3).

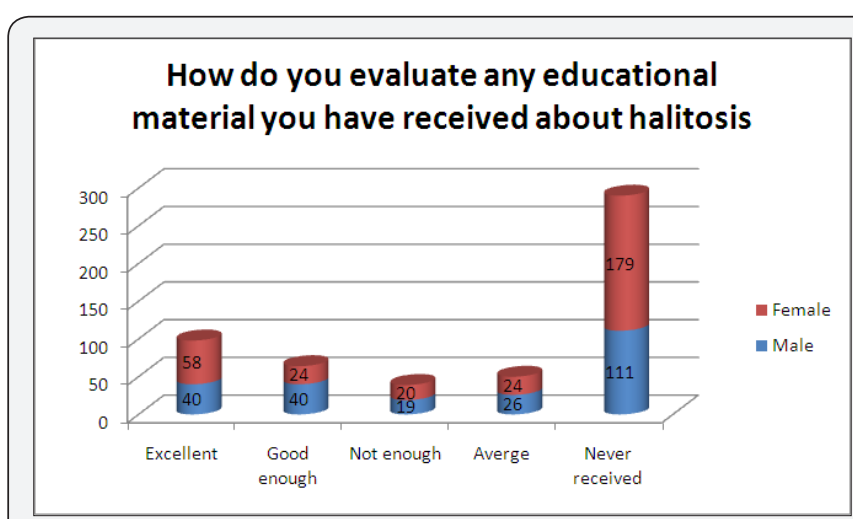

Figure 3 : How do you evaluate any educational material you have received about halitosis?

Table 4: Diagnosis and solutions of halitosis.

\begin{tabular}{|c|c|c|}
\hline In your opinion & \multirow[b]{2}{*}{$\mathrm{n}=\mathbf{5 4 0}$} & \multirow[b]{2}{*}{$\%$} \\
\hline $\begin{array}{l}\text { What is the main diagnostic method to } \\
\text { detect halitosis? }\end{array}$ & & \\
\hline Chemical testing for odorous gases & 81 & $15 \%$ \\
\hline Examination by smelling & 54 & $8.3 \%$ \\
\hline Upper endoscope & 66 & $12.2 \%$ \\
\hline $\begin{array}{l}\text { Measure the proportion of sulphides in the } \\
\text { expired air }\end{array}$ & 65 & $12 \%$ \\
\hline I don't know & 283 & $25.4 \%$ \\
\hline \multicolumn{3}{|l|}{$\begin{array}{l}\text { Suitable solution for a patient with outside } \\
\text { mouth halitosis }\end{array}$} \\
\hline Transfer him to specialized doctor & 390 & $72.2 \%$ \\
\hline $\begin{array}{l}\text { Give the patient proper instructions to clean } \\
\text { the mouth and treat any related oral causes }\end{array}$ & 119 & $22 \%$ \\
\hline $\begin{array}{l}\text { Give the patient proper instructions to } \\
\text { how clean the mouth and transfer him to } \\
\text { psychologist }\end{array}$ & 23 & $4.3 \%$ \\
\hline Transfer him to psychologist & 8 & $1.5 \%$ \\
\hline \multicolumn{3}{|l|}{$\begin{array}{l}\text { Who is the health practitioner who is } \\
\text { qualified to be the first to see a patient } \\
\text { suffering from halitosis? }\end{array}$} \\
\hline Gastroenterologist & 82 & $15.2 \%$ \\
\hline Dentist & 315 & $58.3 \%$ \\
\hline ENT specialized & 53 & $9.8 \%$ \\
\hline General practitioner & 86 & $15.9 \%$ \\
\hline Other & 4 & $0.8 \%$ \\
\hline $\begin{array}{l}\text { What is the correct way to deal with } \\
\text { halitosis? }\end{array}$ & & \\
\hline
\end{tabular}




\section{Global Journal of Otolaryngology}

\begin{tabular}{|c|c|c|}
\hline Nothing. Its existence is normal & 7 & $1.3 \%$ \\
\hline Chewing gum & 78 & $34.4 \%$ \\
\hline Use mouthwash & 194 & $45.6 \%$ \\
\hline Visit the doctor & 246 & $2.8 \%$ \\
\hline Other & 15 & 65.6 \\
\hline About halitosis, do you think & 354 & 18.1 \\
\hline It is easy to treat & 98 & 1.5 \\
\hline It is difficult to treat & 8 & 14.8 \\
\hline Can't be cured & 80 & \\
\hline I don't know & & \\
\hline
\end{tabular}

Regarding the awareness of halitosis, $53.9 \%$ of participants stated that they did not feel prepared to impart advice and provide solutions about halitosis. 94.3\% participants thought that halitosis negatively affected life and $63.7 \%$ reported that they had not been told before that they have bad breath (Table 5). There was no statistically significant difference in the responses of both medical and non-medical participants about being told that they have bad breath. On the other hand, it was significantly different in both genders, as males were more frequently told that they have bad breath $(\mathrm{p}=0.001)$. When asked if they were able to give advices about halitosis, there was no statistically significant difference in the response of any of the genders and specialties ( $p>0.05)$. Moreover, responses of both genders for thinking that halitosis can affect life negatively were not statistically significant either (Table 6).
Table 5: General awareness of halitosis $(n=540(100 \%))$.

\begin{tabular}{|c|c|c|}
\hline & Yes & No \\
\hline $\begin{array}{c}\text { Do you feel you are able to give } \\
\text { advices and solutions about halitosis }\end{array}$ & $249(46.1 \%)$ & $291(53.9 \%)$ \\
\hline $\begin{array}{c}\text { Do you think that halitosis can } \\
\text { negatively affect the person's life }\end{array}$ & $509(94.3 \%)$ & $31(5.7 \%)$ \\
\hline $\begin{array}{c}\text { Have you ever been told that you } \\
\text { have bad breath smell and feel } \\
\text { embarrassed }\end{array}$ & $196(36.3 \%)$ & $344(63.7 \%)$ \\
\hline
\end{tabular}

Table 6: The relation between gender and specialty with halitosis.

\begin{tabular}{|c|c|c|c|c|c|c|}
\hline & Male & Female & $P$ value & Medical specialty & $\begin{array}{l}\text { Non-medical } \\
\text { specialty }\end{array}$ & $P$ value \\
\hline $\begin{array}{l}\text { Have been told } \\
\text { you have bad } \\
\text { breath smell }\end{array}$ & & & 0.001 & & & 0.502 \\
\hline Yes & $104 \quad(44.1 \%)$ & $\begin{array}{c}92 \\
(30.3 \%)\end{array}$ & & $\begin{array}{c}85 \\
(37.9 \%)\end{array}$ & $\begin{array}{c}111 \\
(35.1 \%)\end{array}$ & \\
\hline No & $\begin{array}{c}132 \\
(55.9 \%)\end{array}$ & $\begin{array}{c}212 \\
(69.7 \%)\end{array}$ & & $\begin{array}{c}139 \\
(62.1 \%)\end{array}$ & $\begin{array}{c}205 \\
(64.9 \%)\end{array}$ & \\
\hline $\begin{array}{l}\text { Able to give } \\
\text { advices about } \\
\text { halitosis }\end{array}$ & & & 0.467 & & & 0.452 \\
\hline Yes & $\begin{array}{c}113 \\
(47.9 \%)\end{array}$ & $\begin{array}{c}136 \\
(44.7 \%)\end{array}$ & & $\begin{array}{c}99 \\
(44.2 \%)\end{array}$ & $\begin{array}{c}150 \\
(47.5 \%)\end{array}$ & \\
\hline No & $\begin{array}{c}123 \\
(52.1 \%)\end{array}$ & $\begin{array}{c}168 \\
(55.3 \%)\end{array}$ & & $\begin{array}{c}125 \\
(55.8 \%)\end{array}$ & $\begin{array}{c}166 \\
(52.5 \%)\end{array}$ & \\
\hline $\begin{array}{l}\text { Halitosis can affect } \\
\text { life negatively }\end{array}$ & & & 0.090 & & & 0.003 \\
\hline Yes & $\begin{array}{c}227 \\
(96.2 \%) \\
\end{array}$ & $\begin{array}{c}282 \\
(92.8 \%)\end{array}$ & & $219(97.8 \%)$ & $290(91.8 \%)$ & \\
\hline No & $\begin{array}{c}9 \\
(3.8 \%)\end{array}$ & $\begin{array}{c}22 \\
(7.2 \%)\end{array}$ & & $5(2.2 \%)$ & $26(8.2 \%)$ & \\
\hline
\end{tabular}




\section{Global Journal of Otolaryngology}

\section{Discussion}

Halitosis is an embarrassing change in breath odour that has a negative social impact, affecting many people around the world. Many resources were invested in products to help improve oral malodour with little success. Halitosis causes social and personal isolation, decreases life quality and may indicate the presence of a more severe disease [21]. According to our knowledge, this study is the first evaluation of knowledge and awareness of halitosis conducted in Taibah University, AlMedinah. The response rate of $45 \%$ in the present study was rather low and not in line with the increasing response rates of the two recent cross-sectional surveys conducted over the past three years in Saudi Arabia [22,23]. Both surveys were conducted on the knowledge and self-perception of halitosis, and the obtained response rates were $89 \%$ [22] and $72 \%$ [23].The latest study (2017) [22] was a cross-sectional survey conducted on female participants in King Saud University's women campus, who responded to a questionnaire on the selfperception, knowledge and awareness of halitosis. The other one (2015) [23] was a cross-sectional survey carried out on Saudi adult patients visiting the College of Dentistry and King Khalid University Hospital, King Saud University, Saudi Arabia. The survey used an 18-point self-administered questionnaire on the self-perception of halitosis.

The socio-economic factors in this study included gender, age, marital status, nationality, specialty, academic degree and level of study. Both males and females in our study had a high education level; they were college students. All participants in the latest survey being females, only age and education levels were comparable (details on college major and age were provided) [22]. Al shehri et al. has provided information about the participants' age, gender and marital status but not their level of education [23]. His study received more male respondents (77\%) compared to our study ( $43.7 \%$ males). However, the levels of the age of participants were comparable. The classification of halitosis includes categories of genuine halitosis, pseudohalitosis and halitophobia. Genuine halitosis is defined as obvious malodour that goes beyond the socially acceptable levels. Genuine halitosis is subdivided into physiological and pathological halitosis. Physiological halitosis is temporary and caused by the body's normal metabolic functions, such as hunger, reduced salivation during sleep and temporary halitosis due to certain dietary factors, such as eating garlic [24]. In the present study, majority of the respondents have correctly identified the cause of halitosis to be physiological: after eating strong smelling food ( $92 \%$ of the respondents), malodour in healthy individuals after sleeping (72\%) and halitosis after smoking (71\%).

Pathological halitosis can have intra- and extra-oral causes. It is thought that disorders of the oral cavity cause $56 \%$ to $85 \%$ of all cases of halitosis [24]. Majority of the respondents of the study conducted by $\mathrm{Al}$ shehri et al. agreed that intra-oral diseases, such as periodontal disease (83\%), decayed teeth (80\%) and tongue coating (68\%) are the major causes for halitosis [23]. Similarly, majority of the respondents (97\%) in this study believed that intra-oral diseases are the main causes of halitosis. This is in agreement with a previous study that showed that up to $85 \%$ causes of halitosis originate from oral cavity [25]. However; most of our participants $(40 \%)$ said that the stomach was the most frequent pathological cause of halitosis. This result stood in a stark contrast to what their view articles said, which indicated tongue coating as the major site for oral malodour production, while the stomach was referred to as a rare cause of halitosis [26,27].

This inconsistency might be due to the fact that most of the respondents misconceived stomach-originated halitosis as an intra-oral cause, and since majority of the students did not receive enough education on halitosis (69\%), 53\% of the students said that they had never received any education. Moreover, this could be explained by the poor students' extent of knowledge, as they did not receive educational material on the subject. There were similar findings in the two previous studies (a Portuguese study [28] and a Saudi study [22]), where majority of the participants cited the stomach as the main cause of halitosis. Moreover, this goes with the fact that the general public, dentists and many physicians are still poorly informed about the etiology of halitosis, as many still believe that oral malodour originates in the stomach [29]. Regarding the different aspects of the etiology of halitosis, majority of our respondents had correctly answered 9 out of 15 questions about the different medical conditions and their relation to bad breath. The majority (80\%) thought that eating certain types of food was related to bad breath. This correlates with the view held by most of the respondents who believed that the stomach is the main source of halitosis.

In a comparison study between the dentists and dental hygienists of Switzerland, Germany and France, regarding their knowledge on halitosis, stress and medication were pointed to by the French participants as the most common cause of halitosis [30] This was not the case in our study, as factors like stress, medications, rhinitis, and lung and liver diseases came down on the list with stress being the least related condition to halitosis. While halitosis has several different physiological and pathological etiologies, we stated only 15 medical conditions that can be related to bad breath. The vast majority of the students $(82 \%)$ thought that these are the only conditions that can be related to halitosis, and only a minority related bad breath correctly to a few unspecified conditions, such as depression and kidney diseases. Accordingly, we can say that the students' knowledge regarding the different aspects of the etiologies of halitosis was insufficient. In the present study, the majority of the respondents $(25.4 \%)$ did not know the gold standard methods for halitosis, and only $15 \%$ of them considered chemical testing for odorous gases as the main gold standard clinical method to detect halitosis.

However, Mubayrik et al. [22] showed that the gold standard method for halitosis diagnosis is the organoleptic evaluation. The majority of the respondents $(82.4 \%)$ in the previous study by al 
Mubayrik et al. saw that the most qualified health professionals to treat halitosis are dentists, which is parallel to the results of our study, in which $58.3 \%$ respondents believed the same. Regarding halitosis treatment, the majority of respondents thought that it was easy to treat halitosis. In contrast, Greenman et al. mentioned that it is difficult to assess if the treatment of halitosis is easy and successful, because it is dependent on the clinical experience of physicians or dentists [31]. In the latest study that was conducted on female students from King Saud University, the majority were unwilling to tell a friend or colleague about his/her bad breath [22], which was almost the same case in our study, as $63.3 \%$ of the participants said that they had not been told before that they had bad breath and felt embarrassed.

\section{Conclusion}

In conclusion, knowledge and awareness regarding the different aspects of halitosis seem to be relatively insufficient among Taibah University students, as half of them have never been educated on the topic. Therefore, health officials in the community must increase their efforts in educating the society about this serious problem.

\section{References}

1. Hughes FJ, McNab R (2008) Oral malodour-a review. Arch Oral Biol 53:1-7.

2. Bornstein MM, Stocker BL, Seemann R, Bürgin WB, Lussi A (2009) Prevalence of halitosis in young male adults: A study in Swiss army recruits comparing self-reported and clinical data. J Periodontal 80(1): 24-31.

3. Settineri A, Mento C, Gugliotta S, Saitta A, Terranova, et al. (2010) Selfreported halitosis and emotional state: Impact on oral conditions and treatments. Health Qual. Life Outcomes 8: 34-44.

4. ADA Council on Scientific Affairs (2003) Oral malodor. J Am Dent Assoc 134 (2): 209-214.

5. Bornstein MM, Kislig K, Hoti BB, Seemann R, Lussi A (2009) Prevalence of halitosis in the population of the city of Bern, Switzerland: A study comparing self-reported and clinical data. Eur J Oral Sci 117(3): 261267.

6. Nachnani S (2011) Oral malodor: Causes, assessment, and treatment. Compend Contin Educ Dent 32(1) 22-24.

7. AlSadhan SA (2016) Self-perceived halitosis and related factors among adults residing in Riyadh, Saudi Arabia. A cross sectional study. Saudi Dent J 28(3): 118-123.

8. Sanz M, Roldan S, Herrera D (2001) Fundamentals of breath malodour. J Contemp Dent Pract 2(4): 1-17.

9. Scully C, Porter S, Greenman J (1994) what to do about halitosis. BMJ 308(6923): 217-218.

10. Kasap E, Zeybe M, Yüceyar H (2009) Halitosis. GüncelGastroenteroloji 13: 72-76.

11. Van den Broek AM, Feenstra L, de Baat C (2007) A review of the current literature on aetiology and measurement methods of halitosis. J Dent 35(8): 627-635.
12. Ansai T, Takehara T (2005) Tonsilloliths as a halitosis-inducing factor. Br Dent J 198(5): 263-264.

13. Attia EL, Marshall KG (1982) Halitosis. Can Med Assoc J 126(11): 12811285.

14. Amir E, Shimonov R, Rosenberg M (1999) Halitosis in children. J Pediatr 134(4): 338-343.

15. Monteiro-Amado F, Chinellato LE, de Rezende ML (2005) Evaluation of oral and nasal halitosis parameters in patients with repaired cleft lip and/or palate. Oral Surg Oral Med Oral Pathol Oral RadiolEndod $100(6): 682-687$.

16. Lanza DC (2004) Diagnosis of chronic rhinosinusitis. Ann OtolRhinolLaryngol 193 (Suppl 1): 10-14.

17. Eli I, Baht R, Koriat H, Rosenberg M (2001) Self-perception of breath odor. JADA. 132(5): 621-626.

18. Azod0 CC, Osazuwa-Peter N, Omili M (2010) Psychological and social impacts of halitosis. A review. J Soc Psychol Sci 3: 74-91.

19. Aylikci BU, Colak H (2013) Halitosis: From diagnosis to management. J Nat Sci Biol Med 4(1): 14-23.

20. Kasap E, Zeybe M, Yüceyar H (2009) Halitosis. GüncelGastroenteroloji 13: $72-6$.

21. Dadamio J, Van Tournout M, Teughels W, Dekeyser C, Coucke W, et al. (2013) Efficacy of different mouthrinse formulations in reducing oral malodour: A randomized clinical trial. J ClinPeriodontol 40(5): 505513.

22. Azizah Bin Mubayrik, Al Hamdan R, Al Hadlaq EM, AlBagieh $\mathrm{H}$, AlAhmed D, et al. (2017) Self-perception, knowledge, and awareness of halitosis among female university students. Clinical, Cosmetic and Investigational Dentistry 9: 45-52.

23. Alshehri FA (2016) Knowledge and attitude of Saudi individuals toward self-perceived halitosis. The Saudi Journal for Dental Research 7(2): 91-95.

24. Halitosis JC (2009) Are dentists being prepared for this challenge? A questionnaire survey in a dental school. Portuguese Faculty.

25. Yaegaki K, Coil JM (2000) Examination, classification, and treatment of halitosis; clinical perspectives. J Can Dent Assoc 66: 257-261.

26. Quirynen M, Dadamio J, Van den Velde S, De Smit M, Dekeyser C, et al. (2009) Characteristics of 2000 patients who visited a halitosis clinic. J ClinPeriodontol 36(11): 970-975.

27. Outhouse TL, Al-Alawi R, Fedorowicz Z, Keenan JV (2008) Tongue scraping for treating halitosis. Cochrane Database Syst Rev 19(2):CD005519.

28. Van den Broek AM, Feenstra L, de Baat C (2007) A review of the current literature on aetiology and measurement methods of halitosis. J Dent 35(8): 627-635.

29. Oppliger N, Roth B, Filippi A (2014) Knowledge of halitosis among dentists and dental hygienists. Swiss Dent J 124(2): 133-143.

30. Odai CD, Azodo CC, Osazuwa PN, Obuekwe ON (2011) Characteristics and treatment outcome of patients with halitosis at a suburban health facility. IJBHS 7: 63-72.

31. Greenman J, Duffield J, Spencer P, Rosenberg M, Corry D, et al. (2004) Study on the 24 organoleptic intensity scale for measuring oral malodor. J Dent Res 83: 81-85. 
CC (i) This work is licensed under Creative BY DOI: $10.19080 / \mathrm{GJO} .2018 .12 .555843$
Your next submission with Juniper Publishers will reach you the below assets

- Quality Editorial service

- Swift Peer Review

- Reprints availability

- E-prints Service

- Manuscript Podcast for convenient understanding

- Global attainment for your research

- Manuscript accessibility in different formats

( Pdf, E-pub, Full Text, Audio)

- Unceasing customer service

Track the below URL for one-step submission https://juniperpublishers.com/online-submission.php 